\title{
Reputation asset and environmental liability
}

\author{
R. Sjöblom ${ }^{1,2} \&$ S. Lindskog ${ }^{3}$ \\ ${ }^{1}$ Waste Science and Technology, Lulea University of Technology, Sweden \\ ${ }^{2}$ Tekedo AB, Sweden \\ ${ }^{3}$ Firma Lindskog, Stockholm, Sweden
}

\begin{abstract}
The second largest asset to a company may well be its good reputation. Environmental liabilities warrant special attention in this regard since they may well constitute the largest uncertainty in an annual report, and it is not seldom discovered that they have been underestimated. The purpose of the paper is to compile and present a road map as to how to meet the legal and other requirements, and to analyse the alternatives of proactive and reactive approaches. The legal requirements are to be found in various pieces of legislation, on different topics, and with a highly varying degree of detail. It is found that general statements, including the polluter pays principle, together with the requirements on annual reporting provide a good basis for developing a company strategy. Further information about how to plan for decommissioning and restoration, including financial planning can be found in various recommendations and standards from e.g. IAEA, OECD/NEA and ASTM, and support on cost methods is available from AACE and ISPA. More detail can be found in various open sources such as journal articles, conference proceedings and books. It is concluded that a proactive strategy, which includes early technical and financial planning, is associated with the lowest overall costs, and can eliminate many of the otherwise potentially very troublesome cost raisers. It is also concluded that with proper planning, funding is to be made using untaxed assets. Using taxed assets can constitute an efficient road block against proper decommissioning and remediation actions. It is concluded that a proactive and proper management of environmental liabilities - if properly communicated can constitute an important asset in terms of raised confidence among share holders, customers, interested parties and others.
\end{abstract}

Keywords: Sweden, environmental liability, decommissioning, remediation, nuclear, reputation, asset, cost calculation, financing. 


\section{Introduction}

Literature on management of companies frequently dwell on the issue of the value of a company and its shares. Such evaluations include not just the value according to the financial statements, but also various other intangible assets and liabilities that influence a company's status, and especially its ability to adjust to changing conditions and to succeed in the future.

Of course, a company's future rests on a number of prerequisites, several of which are essential. Nonetheless, such prerequisites are frequently ranked, and it is often put forward that a company's most valuable asset is its personnel (i.e. its human resources). Admittedly, this is sometimes maintained even by companies that obviously more or less abuse their staff, but only attempt to deceive society around them. Nonetheless, the extreme importance of the personnel is widely recognized. Other assets mentioned include the information in a company's computer data bases, inventions, customers, etc., but there is an increasing awareness of the enormous significance of the reputation, and it is frequently ranked second after the personnel [1].

Of course, the management literature, e.g. [1], focuses on fraud, corruption and scandals, and emphasizes the necessity of a high ethical standard and its implementation in the entire organization. But a Corporate Social Responsibility (CSR), comprises many elements, and each of them needs to be properly dealt with. Confidence and reputation may take decades to build and establish, but they can be ruined overnight by some serious misjudgement.

Confidence building is not window-dressing that can be delegated to some public relation function. It has to be for real, or the difference between word and deed will be detected and the credibility lost, probably to a level lower than that in the first place.

To be for real implies that all the different aspects of credibility and reputation need to be attended to. There are specific difficulties of different kinds in the various areas, but it is possible that the issue of environmental liability is the toughest one of them all to manage.

It is frequently put forward [1] that the drawbacks of new and exotic technologies such as nuclear technology and power are overestimated in comparison to well-known hazards, e.g. walking in staircases (which actually constitutes one of the major risks in industrial activities). But the potential problems associated with such new technologies cannot simply be dismissed by referring to superstition among the populace. Accidents do happen, and environmental liabilities are frequently, or even notoriously, underestimated for a number of reasons.

The reputation and confidence building with regard to safety and environmental liability should be sufficiently robust to withstand the scrutiny of various parties, including the "interested parties" and the "educated public". It is also necessary for it to withstand the tests of time, or else any skeletons in the closet will eventually appear as haunting ghosts. 
Industrial activities may sometimes be associated with substantial environmental liabilities. An example of such an activity is nuclear power. Already in the year 1979, it was estimated [2] that the cost for decommissioning a nuclear power reactor would amount to $10-15 \%$ of that for building a new one. The capital cost for nuclear electric power is high, and so is the cost for decommissioning. The value quoted corresponds to the correct order of magnitude also for modern estimates [3] on modern full-size nuclear power plants, i.e. plants without any major deviations from normal operation. The percentage is typically much higher for older facilities, and especially for old research facilities. In cases of malfunctioning, costs can be much higher, and total cost may e.g. multiply in comparison with the one estimated if and when substantial leakage of radioactivity to soil is being discovered (see [4], section 3.6).

\section{Objectives and scope}

Navigating in this relatively new area of environmental liability management is not trivial, and even large and competent companies frequently face difficulties. Justifiably, one might wonder why extraordinarily competent companies, e.g. in the area of nuclear technology, would allow themselves to have to endure the embarrassment of first holding out the prospect of more or less exact estimates and later having to present large deviations that may even vary from time to time.

The present authors have reported previously on such tendencies in Sweden, see References [3, 5-11] and references therein, see also [4], but the work has also included international comparison and especially the analysis in [6] shows that this is actually an international issue.

Most of the previous work by the present authors [3, 5-11] and references therein, has focussed on the "technical" prerequisites for proper cost estimates including the uncertainty in the estimate. This will not be repeated here, but a summary is provided in Section 4.

However, there is also a question of the mind-set, and of the difficulties in compiling the various fragments of prerequisites for a full perspective and a comprehensive undertaking.

The prerequisites are to be found in legislation, standards, guidelines, recommendations, articles and books. The degree of detail can vary immensely, and this can be a treacherous aspect. It is not the purpose of the present paper to provide an extensive summary of all this, but to provide a road map, such that companies, hopefully, more easily can find their way through all the sources of information. Similarly, the purpose is also to facilitate for authorities to find appropriate focus for their oversight.

Another purpose of the present paper is to support companies in their quest for a proper strategy, such that they will maintain and improve their good reputation as well as ameliorate the associated business opportunities. For this purpose, alternative approaches regarding the management of environmental liabilities are analysed. 


\section{Environmental liabilities and estimation}

In most cases, the purpose of a cost estimation of an environmental liability is to provide a basis for accumulation of funds to cover future costs such that adequate but not superfluous funding is available at the time when it is needed. Close to the time of the actual operation, estimation is also carried out for the purpose of execution of the actual decommissioning work.

A cost estimation has a meaning only when the error margin can be presented. In principle, a large uncertainty should correspond to a large capacity to pay over and above the balance in the fund. So there is an incentive to keep the error low. But at the same time, precise estimations of events to take place maybe decades into the future may be difficult and costly to make.

It has been estimated that an error of $\pm 20 \%$ may be attainable for decommissioning nuclear installations in favourable cases [10]. It should be realized that the precision in cost estimates for decommissioning is typically considerably more uncertain as compared to the construction of corresponding new facilities.

Ideally, decommissioning should start already at the design phase and be a part of the continued work and operation of the facility. If not, such planning should be instituted immediately.

Selection of methods to be used is crucial. Alternative methods should be studied, and there should be preparedness to change methods depending on the development of the knowledge base including experience from actual operation.

Radiological surveying is critical for the planning. Thus, radiological mapping for financial estimation purposes need not be comprehensive, but should cover enough to support the precision intended.

When outcomes differ from incurred costs, the deviations are seldom the same for all items. Instead, most of the differences typically occur for a small number of cost raisers. In many cases, such items could have been foreseen by means of a special uncertainty analysis involving e.g. methods similar to those used in safety assessments. Further detail can be found in Reference [10].

Cost structuring and good databases on costs for previous decommissioning operations are crucial, and should not be underestimated or deferred to a later date. It is interesting to note that the method frequently used is the bottom-up method, according to which detailed summations are made over many items, a method that is otherwise used mostly at late stages of planning. The parametric method, using parameters and scaling factors based on a number of previous projects, is used only marginally, whilst in ordinary cost calculation work, this method is normally used for early stages (see [3] for further detail).

\section{Legislation}

\subsection{Some prerequisites}

Industrial production is necessary for the well-being of man and the welfare of society. Consequently, it is accepted that natural resource be used, hazardous 
substances handled, and that there exists risks for damage and injuries. But they must be limited to acceptable levels so that health and environment are protected and the development sustainable. This is the responsibility of every individual and legal person. Legislation, as well as authority oversight, is in place in order to support the various entities to fulfil these requirements, and to ensure that all comply. However, compliance with all requirements does not imply any lifting of responsibility to anyone else (e.g. to a permitting authority). The full responsibility for health, environment, safety and sustainable development stays with the operator and owner. This is the case even after cessation of operations, unless the Government or an authority under it has issued a document stating that all environmental liabilities have been dealt with in full.

Thus, one should stay clear of what is not allowed, and avoid any twilight zones. This may be easier in practice in those cases where legislation is detailed, but this is not always the case. Similar operations may be carried out under not only different legislations, depending on how a case is classified, but also under legislations with highly different degrees of detail. An example of this regarding a fuel as waste or product is discussed in [12]. It is found that legislation expressed only in general terms is just as valid and forceful, and must protect e.g. health and the environment just as well as any detailed legislation. Legislation formulated in general terms may allow more room for solutions that might be more suitable for a company to implement, but requires, on the other hand, more of efforts from a company to ensure e.g. that health and the environment are fully protected. On the other hand, detailed legislation may be easier to interpret and comply with but may hamper developments of efficient techniques and economic growth. Legislation expressed in general terms should be interpreted as a trust in the ability of companies and branches to comply with the intent.

The issue of detail in the legislation is a treacherous one in that absence of detailed rules must not be interpreted to mean that there are none. This is one of the main issues that has prompted the present work.

\subsection{The legal acts}

Legislation within the EU is harmonized to a large extent, although the exact outlines and wordings may differ. Legislation may be quite similar also in many other countries, in particular when it comes to general provisions such as the following extracts from Chapter 2 in the Swedish environmental code [13].

- $\quad$ "Persons who pursue an activity ... must possess the knowledge that is necessary in view of the nature and scope of the activity or measure to protect human health and the environment against damage or detriment."

- $\quad$ "Persons who pursue an activity ... shall implement protective measures ... that are necessary in order to prevent ...detriment to human health or the environment ..."

- "... the best possible technology shall be used in connection with professional activities."

- "Persons who pursue an activity or take a measure shall conserve raw materials and energy and reuse and recycle them wherever possible...." 
- "The rules of consideration ... shall be applicable where compliance cannot be deemed unreasonable. ..."

- $\quad$ "Persons who pursue or have pursued an activity ... that causes damage or detriment to the environment shall be responsible, until such time as the damage or detriment ceases, for remedying it ...."

The obvious conclusion of the above statements is that for a company to be able to fulfil its obligations, it is necessary that funds are set aside during the operation of a facility so that they will be available at the time when they are needed for decommissioning and restoration.

Detailed requirements to this end to have been instituted in various types of legislative documents, in different areas, and at various levels. A clear international legislation in this regard is through the legal requirement in many countries for large companies that they must follow International Accounting Standards, IAS [14], and the International Financial Reporting Standard, IFRS [15]. This is e.g. the case for all countries in the European Union through an EU regulation [16] (which is effective in all the EU countries without any national legislation).

Chapter 37 of IAS deals with "provisions, contingent liabilities and contingent assets". It states that "decommissioning costs for an oil installation or a nuclear power station" constitutes a liability (see section 19). It also states (in sections 25 and 26 that "Except in extreme cases, an entity will be able to determine a range of possible outcomes and can therefore make an estimate of the obligation that is sufficiently reliable to use in recognising a provision" (a provision is a type of liability). Moreover, "In the extremely rare case where no reliable estimate can be made, a liability exists that cannot be recognized. That liability is disclosed as a contingent liability ...". In other words, in the vast majority of cases environmental liabilities are to be declared as costs expressed in currency units. When the cost figure is uncertain, scenario analysis is to be applied to form the basis for such a figure and to at least illuminate the issue of uncertainty. It is natural that such analyses be included in the annual reports.

There are penalties involved for noncompliance, and the harshest ones can be found in the related parts of the penal laws of the various countries.

In addition, specific legislation may apply to various areas. There is no regulation or directive within the EU on financing of nuclear decommissioning, but there is a recommendation from the Commission [17]. It states that funds, preferably segregated ones, should be set aside during the operation of the various facilities to cover all future costs. It recommends that recurrent cost calculations be made and that they are reviewed by a competent authority. This is essentially what has been in existence in Sweden for around 35 years [7]. An excellent compilation of the situation in Sweden and other EU countries can be found in Reference [18].

Assurance of financing of environmental liabilities can also be accomplished by means of securities, and this is the case in Sweden in conjunction with final covering of landfills [13].

It should be recognized that decommissioning and restoration also falls under a number of other acts of legislation, e.g. regarding annual reporting, accounting, 
working environment, permitting, chemical substances, radiation protection, nuclear activities, and acceptance of waste at landfills. It is imperative that a company makes sure that all relevant acts and their requirements are identified and included in the process. They must all be complied with simultaneously.

\section{Standards and recommendations, etc.}

Recommendations, standards, guidelines, and other relevant sources of information on good technology serve many purposes, one of which is to ensure compliance with the legislation, and especially such legislation that is not very detailed.

Recommendations and standards, etc. are not (in general) legally binding, but frequently represent best knowledge and practices in the areas covered. In addition, they are often issued by organizations having excellent reputations and this enhances their credibility. Contrary to what is the case with legislation, an individual company may (in general) deviate from e.g. branch recommendations and standards. Such alternative routes must be taken with caution, however, since the company will then have to come up with all the proof needed on the suitability of the alternative chosen.

For example, in the area of nuclear technology, the International Atomic Energy Agency, IAEA, that operates under the auspices of the United Nations has issued a number of standards in the form of "safety standards", "safety guides" and similar, see e.g. [19-26].

The Nuclear Energy Agency of the Organisation for Economic Co-operation and Development, OECD/NEA has also published a number of reports on decommissioning of nuclear facilities, and in particular, a kind of chart for accounts for cost calculations. It has recently become upgraded and is now referred to as a "standard guide" [27].

ASTM International was originally ASTM (American Society for Testing and Materials), but is now an international organization with members from 120 countries. It has issued several standards with particular relevance to decommissioning and restoration in general (i.e. not only to nuclear facilities) [28-34]. They relate to the following topics:

- Decommissioning plans;

- $\quad$ Cost and liability estimation;

- Disclosure of environmental liabilities;

- $\quad$ Practice for environmental assessments;

- $\quad$ Practice for environmental surveys.

The standard on cost estimation [29] has an approach in concordance with the statements in IAS [14], but provides much more detail, as expected. It prescribes that scenarios be developed and a weighted average be calculated using the costs for the various scenarios. It also discusses and emphasizes the necessity of informing about uncertainty in a pertinent manner, and states that "The estimator should select that measure which most clearly communicates to the user the nature of the uncertainty being evaluated." 
General information on techniques for cost estimation can be obtained from the Association for the Advancement of Cost Engineering, AACE International, and the International Society for Parametric Analysis, ISPA. The latter organization has even published a handbook [35].

The AACE recurrently maintain that any cost estimate must include information on the uncertainty. It is very different at the various stages of a project, and for new build, this may amount to perhaps $+199 /-30 \%$ at a first stage, and $\pm 5 \%$ for the last one. They also put forward that different methods of estimation should be used at different stages, such that parametric methods are preferable at early stages and bottom-up methods at late ones. This is discussed in Reference [3]. ISPA's handbook [35] deals with parametric methods.

Further information can be found in a large number of conference proceedings, journal articles and books. They can provide excellent support in a general sense, but the help can also be very specific, especially if information can be found on a completed project regarding a similar facility. An example of the latter can be found in Reference [5].

\section{Discussion and conclusions}

One major obstacle for technically oriented people to overcome in conjunction with planning for decommissioning and cost estimation is why it should preferably be carried out at an early stage, perhaps decades before the actual decommissioning and remediation operations. The simple answer to this rhetorical question has already been given above, namely that it is needed in order for appropriate funding to be set aside. But the answer is also that one needs to have a handle on what will take place during decommissioning in order to prepare for it appropriately. This includes introducing features in the construction that facilitates decommissioning (e.g. simple dismantling) as well as avoidance of spills, and especially spills to soil. If spills take place, nonetheless, they should be documented. Such planning will facilitate decommissioning and make it less expensive.

Thus, a proactive approach rather than a reactive one makes good financial sense. But what about the communication with the outside world, including the share-holders? A generation ago, little was reported publicly from a company regarding its emissions to air and water. Today, many companies issue not only regular financial reports, but also annual environmental statements, e.g. under the voluntary EU regulation of EMAS [36, 37]. Key areas include energy efficiency, material efficiency, water, waste, biodiversity and emissions. Obviously, the focus is on emissions and continuous operation.

Environmental liabilities are rarely included to any extent in financial and environmental reports. Of course, the financial reporting must include liabilities, cf. section 4 above. But a thorough explanation is rarely given and indications of uncertainty are often lacking. In the cases of external funds, this is typically only mentioned, although a company may have to pay much larger fees in the future if the calculations have been overly optimistic. Of course, an external fund system 
is typically combined with authority oversight, but it is nonetheless the company in question that has the full responsibility for the outcome.

Some information on the performance of nuclear power companies in Europe with regard to funding for decommissioning can be found in the EU report [18].

A Swedish report on financial securities in conjunction with landfilling [38] unveils that many companies in Sweden do not declare any environmental liabilities, and those who do, mainly declare taxed assets on grounds of insecurity in relation to the tax authorities and application of the precautionary principle. Actually, this issue was dealt with by the Swedish Government already in 1977 when it concluded in a proposition that money set aside to cover environmental liabilities should not generate taxation [6]. Subsequently a law was passed in accordance with the proposition. Using taxed money is a clear a violation of the IAS/IFRS, cf. section 4 above.

It might appear cautious to set aside taxed money, but a closer analysis shows that the consequences are highly undesirable. Paying actual costs with taxed assets implies that the profit becomes artificially exaggerated (at the time), and with it presumably also the bonuses for the management. However, the opposite effect appears when decommissioning and restoration is to take place. Then, when the costs for decommissioning and restoration are to be paid, they will appear as costs in the accounts, and consequently the profit will become artificially low, or even a loss. Such outcomes are highly unpopular among the shareholders, as well as with the fellow managers who may not get any bonuses. Setting aside taxed assets can thus be expected to constitute an efficient barrier against any initiative to take responsibility and to carry out any actual decommissioning and clean-up operations. This effect is thus the exact opposite of what should be intended with an arrangement for funding of environmental liabilities.

In Sweden, costs for remediation regarding such industrial activities that have ceased before the year 1969 are frequently paid by the tax payers. At present, such operations represent a majority of cases, and there may be decades before this work becomes finished. But as distance to this year increases, so may also the number of cases in which the companies and land owners will have to pay. This will imply that the robustness of the financial preparations will be tested.

Of course, management books on how credibility rules [1] may be helpful in crises where insufficient preparedness is becoming unveiled. But the book [1] also tells about how to build and maintain a good reputation, and also that confidence takes time to build, but can be lost overnight.

The preferable approach, and a better use of management literature, is to apply a proactive strategy. It includes proper technical and financial planning for decommissioning and remediation. This alternative has the highest efficiency and the lowest total cost. It provides financial insight throughout the operation, and makes costs appear in the books at the same time as the earnings are made. Inappropriate planning can have the added cost of disrepute, whilst a proper planning will create confidence and good reputation. Properly communicated, this will strengthen the business, and thus constitute an additional asset. 


\section{Acknowledgements}

Financial support for much of the background material for this paper has been received from the Swedish Radiation Safety Authority and from the Nordic Nuclear Safety Research. Support for this specific paper has been received from Angpanneföreningen's Foundation for Research and Development (Ångpanneföreningens Forskningsstiftelse), but most of the finance has come from the authors.

\section{References}

[1] Diermeier, D., Reputation rules, strategies for building your company's most valuable asset. McGraw-Hill; 1st edition, April, 2011.

[2] Techniques and costs for decommissioning of Swedish nuclear power plants. (In Swedish). SKBF/KBS (now the Swedish Nuclear Fuel and Waste Management Company, SKB), Teknisk Rapport 19-21, 1979.

[3] Sjöblom, R. \& Lindskog, S., Financial planning for the decommissioning of a nuclear power plant. WIT Transactions on Ecology and The Environment, Vol 162, pp. 3-14, 2012.

[4] Laraia M., Editor, Nuclear decommissioning. Planning, execution and international experience. Woodhead Publishing Limited, 2012.

[5] Sjöblom, R., Sjöö, C., Lindskog, S. \& Cato, A., Early stage cost calculations for determination and decommissioning of nuclear research facilities. The 10th International Conference on Environmental Remediation and Radioactive Waste Management. Glasgow, Scotland, 4-8 September, 2005.

[6] Lindskog, S., \& Sjöblom, R., Regulation evolution in Sweden with emphasis on financial aspects of decommissioning. Decommissioning Challenges: an Industrial Reality? Sept. 28 to Oct. 2, 2008 - Avignon, France.

[7] Lindskog, S. \& Sjöblom, R., Radiological, technical and financial planning for decommissioning of small nuclear facilities in Sweden. Proceedings of the 12th International Conference on Environmental Remediation and Radioactive Waste Management, ICEM2009, October 11-15, 2009, Liverpool, UK.

[8] Lindskog, S. \& Sjöblom, R., Implementation of the polluter pays principle - example of planning for decommissioning. WIT Transactions on Ecology and the Environment, Vol 131, pp. 27-38, 2010.

[9] Sjöblom, R. \& Lindskog, S., Management of intergenerational environmental liabilities - example of decommissioning of nuclear research and development facilities. International Journal of Sustainable Development \& Planning, Vol. 7, No. 2, pp. 135-158, 2012.

[10] Andersson, I., Backe, S., Iversen, K., Lindskog, S., Salmenhaara, S. \& Sjöblom, R., Cost calculations for decommissioning and dismantling of nuclear facilities. Nordic Nuclear Safety Research, Project NKS-R, Report number NKS-165, July 2008. 
[11] Sjöblom, R., Lindskog, S. \& Andreas, L., Long term aspects of landfilling and surface disposal - lessons learned from nuclear and non-nuclear decommissioning, remediation and waste management. Journal of Earth Sciences and Geotechnical Engineering, vol. 3, no. 3, pp. 35-51, 2013.

[12] Sjöblom, R., Sustainability of combustion and incineration of renewable fuels: example of Sweden. WIT Transactions on Ecology and The Environment, Vol. 176, pp. 173-184, 2013.

[13] The Swedish Environmental Code. Ds 2000:61, Government Offices of Sweden, Last updated in August 2007. Translation of Miljöbalken, SFS 1998:808.

[14] 2013 International Financial Reporting Standards. International Accounting Standards Board, IFRS Foundation.

[15] International Accounting Standards. International Accounting Standards Board, IFRS Foundation.

[16] Regulation No 1606/2002 of the European Parliament and of the Council of 19 July 2002 on the application of international accounting standards.

[17] Commission recommendation of 24 October 2006 on the management of financial resources for the decommissioning of nuclear installations, spent fuel and radioactive waste.

[18] Communication from the Commission to the European Parliament and the Council on the use of financial resources earmarked for the decommissioning of nuclear installations, spent fuel and radioactive waste. Brussels, 2013. This reference includes an accompanying Commission staff working document.

[19] Decommissioning of nuclear power plants and research reactors. Safety Guide. IAEA safety standard series No WS-G.2.1. Vienna, 1999.

[20] Decommissioning of Nuclear fuel cycle facilities. Safety Guide. IAEA safety standard series No WS-G.2.4. Vienna, 2001.

[21] Decommissioning of medical, industrial and research facilities. Safety Guide. IAEA safety standard series No WS-G.2.2. Vienna, 1999.

[22] Predisposal management of radioactive waste including decommissioning. Safety Requirements. IAEA safety standard series No GS-R-2. Vienna, 2000.

[23] Application of the concepts of exclusion, exemption and clearance. IAEA safety standard series No RS-G-1.7. Vienna, 2004.

[24] Classification of radioactive waste. IAEA general safety guide No GSG-1. Vienna, 2009.

[25] Safety assessment for the decommissioning of facilities using radioactive material. IAEA safety guide No WS-G-5,2. Vienna, 2008.

[26] Decommissioning of facilities using radioactive material. IAEA safety requirements No WS-R-5. Vienna 2006.

[27] International structure for decommissioning costing (ISDC) of nuclear installations. OECD/NEA, 2012.

[28] Standard Guide for Nuclear Facility Decommissioning Plans. ASTM standard E1281 89(2005). 
[29] Standard Guide for Estimating Monetary Costs and Liabilities for Environmental Matters. ASTM Standard E 2137 - 06, December 2006.

[30] Standard Guide for Disclosure of Environmental Liabilities. ASTM Standard E 2173 - 07, April, 2007.

[31] Standard practice for environmental site assessments: Phase I environmental site assessment process. ASTM Standard E1527-13, November, 2013.

[32] Standard practice for environmental site assessments: Phase II environmental site assessment process. ASTM Standard E1903-11, June, 2011.

[33] Standard Practice for Expedited Site Characterization of Vadose Zone and Groundwater Contamination at Hazardous Waste Contaminated Sites. ASTM Standard D6235-04(2010).

[34] Standard Practice for Conducting Environmental Baseline Surveys. ASTM Standard D6008-96(2005).

[35] Parametric estimating handbook, 4th edition. International Society for Parametric analysis. April, 2008.

[36] Regulation (EC) No 1221/2009 of the European Parliament and of the Council of 25 November 2009 on the voluntary participation by organisations in a Community eco-management and audit scheme (EMAS).

[37] Commission Decision of 4 March 2013 establishing the user's guide setting out the steps needed to participate in EMAS, under Regulation (EC) No 1221/2009 of the European Parliament and of the Council on the voluntary participation by organisations in a Community eco-management and audit scheme (EMAS) (notified under document $\mathrm{C}(2013)$ 1114). Commission decision 2013/131/EU.

[38] Carlsson, B., Financial securities in conjunction with landfilling. (In Swedish: Ekonomisk säkerhet vid deponering). Report prepared by Envipro Miljöteknik AB, on commission by the Swedish Environmental Protection Agency, EPA, 2004. 